\title{
PROPUESTAS DIDÁCTICAS Y RECURSOS UTILIZADOS EN LA ENSEÑANZA DE LA LECTURA Y LA ESCRITURA EN LAS ESCUELAS PRIMARIAS ${ }^{1}$
}

\author{
Mag. Ruth Cruz* \\ Mtra. Carmen Di Nardo** \\ Mtra. Mabel Galmés*** \\ Dr. Enrique Lorenzo****
}

\section{Justificación}

Desde siempre ha interesado el tema de la enseñanza y el aprendizaje de la lengua escrita. Numerosas investigaciones realizadas en el área informan sobre la preocupante situación en cuanto a los resultados que se observan de los procesos de lectura y escritura. Al respecto, en 1993 Wolff, Schiefelbein y Valenzuela publican un trabajo que refiere al Mejoramiento de la calidad de la educación primaria en América Latina y el Caribe: hacia el siglo XXI (Informe No.28, BID) y señalan que: "En términos de rendimiento académico, los resultados obtenidos por los países de América Latina y el Caribe son significativamente inferiores a aquéllos del mundo desarrollado, siendo inferiores también a los de muchos países asiáticos en desarrollo"(pág.II, Resumen ejecutivo). En ese mismo año, en el Proyecto Principal de Educación en América Latina y el Caribe, Boletín No.30; UNESCO/OREALC, se señala que "Si bien la educación en América Latina ofrece acceso al 94\% de los niños que cada año cumplen la edad para ingresar al sistema escolar, la cantidad de ellos que repiten grados en América Latina es enorme y el problema se acentúa en el primer grado. Cada año repite un $40 \%$ de los alumnos de este nivel, principalmente porque no han aprendido a leer y escribir. De 16.5 millones de alumnos en el primer grado de la educación básica, unos 7 millones repiten; de 12 millones de alumnos del segundo grado, unos 4 millones repiten y de los 11 millones de alumnos del tercer grado, unos 3 millones son repitientes", (pág.4). Con mayor o menor énfasis estas ideas han sido destacadas en otras pesquisas y constituyen sólidos antecedentes para continuar investigando sobre el tema, a efectos de definir líneas de acción que puedan modificar esa realidad. En el documento de Wolff, Schiefelbein y Valenzuela también se señala como muy relevante el contacto con textos para desarrollar adecuadamente las competencias lingüísticas y comunicativas de los alumnos, destacando que "La disponibilidad de libros de textos y otros materiales es uno de los factores fundamentales asociados a la calidad educativa y al rendimiento académico a nivel primario" (pág. VII, Resumen ejecutivo).

La mayoría de las investigaciones se han centrado en los aprendizajes de los alumnos y en el análisis de los materiales de lectura; pero para poder comprender mejor la situación hace falta además conocer las estrategias de intervención y el comportamiento de los docentes en el salón de clase. El estudio de los modelos didácticos aporta información valiosa y facilita la toma de decisiones con referencia a propuestas de mejoramiento en el área. Wolff, Schiefelbein y Valenzuela ya lo habían señalado al decir: "Se tiene escasa información sistemática en América Latina y el Caribe acerca de las prácticas pedagógicas y el comportamiento en la sala de clase de los profesores", (pág.69). En similar línea, un grupo de expertos en el área de la lectura y la escritura recomendaron: "Recuperar, sistematizar y difundir innovaciones exitosas, tanto a nivel regional como local, con la colaboración de universidades, centros de formación magisterial, organismos internacionales y organizaciones no gubernamentales" (Boletín

1 Este trabajo de investigación se desarrolló con la cooperación académica de la Lic. Mirta Castedo (Universidad Nacional de La Plata, Argentina), en el marco de un proyecto financiado por BID/REDUC. 
No.30, Proyecto Principal de Educación en América Latina y el Caribe, UNESCO/OREALC, pág.8). Por lo tanto se torna imperiosa la búsqueda de información sobre las formas y maneras que los docentes tienen de enseñar la lengua escrita. Este informe de investigación pretende, con sus conclusiones y reflexiones, realizar un aporte a la enseñanza de la lengua escrita en el nivel primario, en los países de la región.

\section{Objetivos}

* Describir, a partir de la muestra seleccionada, la situación en la que se encuentra la enseñanza de la lectura y la escritura en las escuelas primarias.

* Categorizar las propuestas didácticas que emergen de los comportamientos de los docentes en el aula.

* Relacionar las propuestas dominantes de enseñanza de la lectura y la escritura con los referentes teóricos más aceptados hoy día.

* Sugerir líneas de acción a efectos de mejorar los procesos de enseñanza y aprendizaje.

\section{Marco teórico}

Dos son los ejes teóricos que enmarcaron la pesquisa: los procesos de enseñanza y los procesos de lectura y escritura. Para respaldar el primero de ellos se ha trabajado con propuestas que presentan a la didáctica como una teoría sobre las prácticas de enseñanza. Los fenómenos de la transposición didáctica, el contrato didáctico y las configuraciones didácticas han sido conceptos claves para poder ir tejiendo el marco teórico de este trabajo de investigación. Camilloni (1995), Chevallard (1997), Litwin (1997), entre otros, han aportado valiosos referentes conceptuales sobre este tema. Por otra parte, la lingüística ha facilitado la definición de "lectura y escritura". En la perspectiva de un paradigma transaccional, Rosenblatt (1996), estos procesos son entendidos fuertemente como construcción de sentido.

\subsection{La naturaleza transaccional del lenguaje.}

Puesto que la visión transaccional es una teoría filosófica acerca del conocimiento, cada disciplina científica puede relacionarse con su objeto de estudio a partir de dicha teoría. En cuanto a la lingüística, Rosenblatt (1996) señala dos corrientes semióticas correlativas a dos modelos teóricos. Así, el estructuralismo y postestructuralismo derivados del pensamiento del suizo Ferdinand de Saussure (1857-1913) responden a la concepción filosófica cartesiana. La doctrina lingüística de de Saussure, en efecto, puede ser reducida a una serie de díadas u oposiciones entre elementos (entre sus dicotomías más famosas se encuentran las de: lengua-habla; sincronía-diacronía; significado-significante...). La dualidad "significante" (imagen acústica)-"significado" (concepto), alentó la visión de la lengua como sistema independiente y autónomo, que es la visión tradicional: sistema o código de reglas y convenciones arbitrarias que hablantes y oyentes reciben del cuerpo social.

Por otra parte, la teoría elaborada por Rosenblatt, que encuentra sus raíces en el fundador de la semiótica estadounidense, Charles Sanders Peirce (1839-1914; matemático y filósofo que siguió a Kant en sus planteamientos e influyó en el pragmatismo y el instrumentalismo a través de William James y Dewey), representa una visión transaccional del hecho lingüístico. No es posible entender a Rosenblatt sin antes comprender la naturaleza en tríada del signo lingüístico formulada por Peirce. Si de Saussure postulaba que el signo tiene dos "rostros" -el del significante y el del significado-, Peirce agrega un tercero: el que tiene que ver con la persona y con la transacción que ésta hace con el mundo. 
La tríada de Peirce es la siguiente: signo, objeto denotado ("significante" y "significado" respectivamente en la terminología saussuriana), y asociación mental (llamado también interpretante); el signo está relacionado con su objeto sólo como consiguiente a una asociación mental. El signo conformado por estos tres componentes constituye un símbolo verbal, expresión que pretende significar más adecuadamente la naturaleza polisémica del signo lingüístico.

¿De qué se trata el elemento "asociación mental" introducido por Peirce? Nos quiere decir que el sentido de una palabra no es adquirido fríamente del cuerpo social, sino que el hablante lo hace suyo en una determinada circunstancia, es decir, en un determinado contexto social, cultural, vivencial. El hablante "internaliza" el sentido de una palabra "al entrar en transacción con un medio ambiente particular". Por ello, el sentido total de aquella está dado por la suma de las vivencias cognitivas, psicológicas, afectivas que tal palabra suscita en el hablante. La "asociación mental" determina el sentido connotativo (connotar: conllevar la palabra, además de su significado propio o específico, otro por asociación) del símbolo verbal. En oposición a de Saussure, Peirce observa que en la adquisición del lenguaje, lo individual cobra una gran relevancia, pues, como puede concluirse, una misma palabra tiene un sentido único y personal para cada hablante, puesto que el símbolo verbal es el resultado de un interpretante en transacción con el mundo concreto que lo rodea. Como el hablante está en permanente transacción, la asociación mental de cada símbolo está sujeta a nuevos cambios y enriquecimientos. Este sentido del símbolo verbal es, en consecuencia, privado, individual, vivencial y predominantemente connotativo (psicológicoafectivo).

Pero, si es así, ¿cómo logra comunicarse una comunidad lingüística? La respuesta hay que buscarla en lo denotado (denotar: significar una palabra o expresión de una realidad en la que coincide toda la comunidad lingüística). Se opone a connotar. El significado representa el sentido léxico o denotativo del símbolo verbal. Es, por tanto, público, social, conceptual y predominantemente cognitivo (es predominantemente cognitivo pues el significado de las palabras puede expresar también connotaciones afectivas públicamente compartidas). Con referencia a este tema Rosenblatt nos dice:

"Para la persona, por ende, el lenguaje es esa parte, o conjunto de características, del sistema público que ha internalizado a través de sus propias experiencias con las palabras en situaciones de la vida real. $<$ Los conceptos léxicos deber ser compartidos por hablantes de un idioma común... y sin embargo, queda margen para una considerable diferencia de persona a persona en lo que hace a los detalles de cualquier concepto $>"$ (1996:21).

Al depósito de las transacciones sociales, culturales, vivenciales, que sobreviven en el interior de un hablante, Rosenblatt (1996) lo denomina reservorio de experiencias lingüísticas. En otras palabras, el "reservorio" no es otra cosa que la historia individual con que cada persona se enfrenta a una nueva actividad lingüística. El reservorio, por lo tanto, está sometido a permanente modificación, corrección y extensión.

\subsubsection{La transacción con el texto}

Hasta aquí se estudió la transacción con el signo lingüístico. Ahora la autora desarrolla su teoría transaccional abordando un nuevo problema: la transacción con el texto. Esto presupone desde ya dos vertientes: la transacción con el texto oral y la transacción con el texto escrito. A Rosenblatt le interesa de modo particular la transacción con este último, el cual, asimismo, admite un triple enfoque: a) la transacción del lector con el texto; b) la transacción del autor con el texto que escribe; c) la transacción del lector con el autor. De todos modos, la autora se refiere sumariamente a la transacción con el texto oral. 


\subsubsection{La transacción con el texto oral}

Se produce en una conversación. ¿De qué modo tiene lugar la transacción con el texto oral? Tanto el hablante como el oyente se enfrentan en esta instancia con su propio reservorio de experiencias lingüísticas, por lo cual los signos verbales emitidos evocarán para uno y otro símbolos verbales diversos. Los papeles de hablante y oyente alternarán y las intervenciones de éste o aquél irán modificando las expectativas, intenciones y sentidos primeros. En la transacción oral participan no sólo el reservorio de cada cual y la interpretacional personal de los signos verbales, sino también el contexto (ambiente, ocasión, presencia física, estado de ánimo) y los signos no verbales (modulación de la voz, gestualidad). Al concluir la conversación se percibe que la misma ha sido el resultado de una transacción a la vez que los interlocutores ya no son los mismos tampoco.

\subsubsection{La transacción del lector con el texto escrito}

El lector concreto, en el momento de tomar un libro, se encuentra en un estado afectivo particular, con ciertas presiones, en un determinado ambiente, en un presente único. Por otra parte posee un cierto reservorio de experiencias lingüísticas. Esta serie de elementos influirá decisivamente en su "postura predominante" (concepto que se verá más adelante) y en su atención selectiva (concepto acuñado por William James (1842-1910), filósofo estadounidense, maestro de Dewey; uno de los primeros psicólogos modernos y gran maestro del pragmatismo) - acción activadora e inhibidora del campo de conciencia - en el proceso de lectura.

Un libro como tal no es más que un objeto que contiene signos marcados sobre un fondo, cuyo conjunto constituye un texto. El libro, por lo tanto, no posee de por sí un significado. No existe un significado preexistente a la lectura. Es la lectura la que hace posible que una sucesión de signos verbales se transforme en un entramado de símbolos verbales. Pero ello es obra del interpretante, el cual construye el significado del texto. A esta actividad del lector como constructor del significado Rosenblatt la llama la evocación del texto. Comporta un hecho complejo, no lineal, pues implica un constante examen de correspondencias que hace el lector entre los últimos signos verbales interpretados y la evocación del texto precedente a ellos, lo cual comprende una permanente operación de selección, organización y síntesis hechos hasta ese instante. Si no tiene éxito, el lector deberá revisar las fallas en su evocación, debidas quizá a incoherencias entre su reservorio y los signos verbales textuales, o a elecciones infelices de su atención selectiva, o a errores en el proceso de operaciones mentales producido hasta entonces, o a perturbaciones acontecidas en el segundo flujo continuo de la respuesta, es decir, en la serie de reacciones, motivadas por aceptación, rechazo, prejuicios, expectativas y conocimientos previos, proyecciones personales producidas en el lector a medida que evoca el texto. Problema que se plantea: ¿cómo discernir con precisión lo que deja de ser evocación del texto para transformarse en respuesta del segundo flujo?

En la transacción con el texto participa de modo destacado también lo que la autora denomina como "postura predominante del lector". El lector adopta una postura predominante eferente cuando su atención selectiva se dirige de manera preferencial al sentido denotativo del símbolo verbal, evocando el texto desde este ángulo lingüístico. Y adopta una postura predominantemente estética cuando su atención selectiva se dirige de manera preferencial al sentido connotativo del símbolo verbal, al complejo de vivencias asociativas que suscita el signo verbal, pero atendiendo también al sentido denotativo de éste. Se trata de una postura compleja, en la cual se integra lo cognitivo con lo sensorial-afectivo-psicológico en una unidad intuitiva:

"Ingresan ahora a la conciencia no sólo los referentes públicos de los signos verbales sino también la parte privada del <iceberg > del significado: las sensaciones, las imágenes, los sentimientos y las ideas que constituyen el residuo de hechos psicológicos pasados relacionados con dichas palabras y referentes" (Rosenblatt, 1996:31) 
Según la autora, el carácter (literario- no literario) de una obra, resulta más de la postura adoptada por el lector que del propio código de signos de la obra, aunque consiente que un lector experimentado automáticamente adopta la postura predominantemente adecuada a las pautas que dicho texto ofrece. Se dice que el lector adopta una postura predominante, puesto que ésta no es ni excluyente ni permanente, sino que puede ser objeto de reiterados cambios en el proceso de lectura. En otras palabras, la postura del lector se mueve en el fluir de su conciencia, en lo que la autora denomina el continuo eferente - estético. Una postura predominantemente eferente puede, en cierto punto, desplazarse hacia una posición intermedia o incluso estética y viceversa. La atención selectiva no está, por tanto, sujeta a un punto determinado del continuo. En la postura predominantemente estética la atención selectiva puede pasar de lo vivencial al análisis eferente-captación de información, actitud de abstracción, de análisis de ideas, de elaboración de estructuras, de formulación de juicios, etc. Pero, en substancia, ambas posturas son distintas. Una lectura eferente puede ser parafraseada satisfactoriamente, a un tercero con apetencia eferente, porque ambos manejan el sentido público y denotativo del lenguaje. Pero una lectura estética no puede ser transmitida a un tercero con apetencia estética, pues la dimensión vivencial no puede ser comunicada, porque es única y privada.

El complejo proceso de evocación del texto pone en evidencia que el texto no posee en sí un significado, sino que es el lector quien lo va construyendo lo va "reescribiendo", hasta que, finalmente, logra interpretarlo, o sea, logra "informar, analizar y explicar la evocación". Interpretar el texto supone develar el sentido de éste como un todo, la elucidación del texto a la luz del "segundo flujo continuo de la respuesta" (que constituye el marco, los límites personales en que la lectura se ha realizado).

\subsubsection{La transacción del escritor con el texto}

$\mathrm{Al}$ igual que el lector, el escritor se enfrenta al proceso de escritura a partir de su propio reservorio de experiencias lingüísticas, como así también de un cierto contexto exterior (el espacio físico, el ambiente, la ocasión particular, las obligaciones) y personal (sus motivaciones, circunstancias biográficas, presiones, estado afectivo). Es decir, en el momento de escribir, el autor es la suma de sus transacciones vitales, pasadas y presentes. La creación escrita que seguirá -y no puede ser de otro modoreflejará esa transacción del escritor con su mundo.

Sin embargo, este proceso de redacción presenta desemejanzas con respecto al propio del lector. Mientras éste interpreta los signos verbales registrados en el papel, el escritor carece de ellos, teniendo frente a sí el papel en blanco. Su transacción entonces se dará, en la etapa inicial, entre los símbolos verbales que elegirá y "un estado orgánico" de ideas y sentimientos o temas más o menos vagos, que constituyen el estímulo inicial que motiva la escritura, y que Rosenblatt (1996) llama la medida interior. La síntesis de todos los elementos expuestos en estos párrafos mueve la actividad de la atención selectiva hacia algún punto del campo de conciencia, del reservorio. Cuanto más conciencia tenga el escritor de la naturaleza transaccional de la redacción, podrá dirigir con mayor acierto su atención selectiva. La focalización de la atención selectiva determina asimismo la postura predominante del escritor en el continuo eferente- estético en virtud de la cual el escritor selecciona determinados signos verbales que pueden servir mejor al sentido público o privado que desea construir. Hay un elemento de suma importancia que influye también en la acción de la atención selectiva y de la postura del escritor, que es el lector virtual, es decir, el lector potencial que supone todo proceso de redacción y que está implícito en todo texto. 
El proceso de escritura hace del escritor también un lector, puesto que éste va leyendo los signos que escribe. Al igual que el lector, el escritor debe evocar su texto, o sea, examinar la correspondencia coherente entre los últimos símbolos verbales lingüísticos escogidos y la construcción del significado hecha hasta entonces a partir del texto precedente. Pero esta actividad de lectura es más compleja que la del lector, puesto que presenta dos orientaciones simultáneas. Por una parte, el redactor hace una lectura orientada hacia la expresión: los símbolos verbales elegidos deben adecuarse a la "medida interior". Por otra parte, el redactor hace una lectura orientada hacia la recepción: el escritor lee, desde esta perspectiva, con los "ojos" del lector virtual, animado por una inquietud: ¿será adecuada esta selección de símbolos verbales para la evocación que hará el lector?

\subsubsection{La transacción del escritor con el lector}

Si el texto es consecuencia de la transacción del escritor con su mundo, la transacción que el lector hace con el texto representa también una transacción con el mundo del escritor. A la transacción de los mundos de lector y escritor se le llama contrato. ¿En qué medida se aproximan las evocaciones de ambos? Esto depende del grado de proximidad entre el reservorio de experiencias lingüísticas de cada lector con el del escritor; en definitiva, entre una vida y otra, pues el reservorio es producto de las experiencias individuales, educativas, socioculturales, sociales, familiares. Más problemática aun la lectura de un texto antiguo, pues el reservorio del autor está muy distante de aquel del lector. ¿Cómo evocarlo si la época actual es tan distinta de aquélla? Si deseamos acercarnos a la "medida interior" del autor deberemos consultar fuentes extra textuales que nos informen de la cultura de entonces, hecho que torna más compleja todavía la transacción. La evocación es otra, muy distinta, si prescindimos de ese puente cultural y emprendemos la transacción únicamente con el "hoy" de nuestro reservorio. El lector, ante esto se pregunta: ¿es válida mi interpretación?. ¿Cómo saberlo si no existe un significado único, absoluto, correcto del texto?. Cada lectura de un mismo texto representa una evocación e interpretación personal, cada texto prefigura infinitas lecturas:

"El mismo texto asume diferentes significados en transacciones con diferentes lectores o aun con el mismo lector en diferentes contextos u ocasiones" (Rosenblatt,1996:48)

¿Cómo evaluar entonces "la relación entre la interpretación del lector y la intención del autor?" Rosenblatt se refiere a este tema a través del concepto de la afirmabilidad garantizada (concepto también de John Dewey). ¿Qué quiere decir esto?: que fijando ciertos criterios de interpretación, y tomando como base un determinado "ambiente cultural compartido" por una categoría de lectores, puede establecerse un cierto marco que delimitaría las interpretaciones válidas y dejaría fuera las inválidas. Se trataría de un margen - y no de la imposición de un significado correcto -, en el cual, además podría juzgarse "ciertas interpretaciones como superiores a otras". Entre los criterios básicos que se pueden fijar para la interpretación válida del texto, la autora menciona los tres siguientes: "que se considere el contexto y el propósito del lector; que la interpretación no entre en contradicción - o que no tome en cuenta - el texto en su totalidad o los signos escritos en la página; que la interpretación no proyecte significados que no puedan relacionarse con los signos escritos en la página" (Rosenblatt, 1996:50)

La teoría transaccional tiene amplia repercusión en el ámbito de la enseñanza de la lectura y de la escritura, dado que se trata de hechos transaccionales que trascienden estas actividades y apuntan a zonas más amplias, como la del aula, la de la atmósfera creada por el maestro, como así también la del contexto institucional, social y cultural del alumno. La enseñanza debe tender a que los alumnos intuyan la complejidad transaccional de sus relaciones con el texto, ya como autores o como lectores. Esto implica asumir nuevos modelos didácticos. 


\subsection{Modelos didácticos}

Las investigaciones sobre la enseñanza han permitido ir incorporando más elementos a la nueva agenda de la didáctica (Camilloni, 1995; Litwin, 1997). Conceptos tales como transposición didáctica (referida a las sucesivas modificaciones que sufre el saber en el momento que se transforma en "saber enseñable"), configuración didáctica (vinculado con las formas o maneras que los docentes tienen de presentar el saber), contrato didáctico (relacionado con las negociaciones y encuentros que se dan en el espacio áulico entre los proyectos de enseñanza y aprendizaje), relación didáctica (referida a las formas de relación interpersonales, próximas y empáticas, determinadas fundamentalmente por la intencionalidad del aprender y del enseñar), situación didáctica (entendida como una instancia donde se enmarcan los proyectos de enseñanza y aprendizaje, se presenta la nueva información y se desarrolla la integración formativa a través de estrategias de aprendizaje; Vázquez, 1999), entre otros, han venido enriqueciendo el debate y la agenda de la nueva didáctica. Estos conceptos serán claves en el momento de analizar los datos.

La incorporación de estos términos supone de alguna manera la construcción de un modelo didáctico; con referencia al término "modelo" es oportuno realizar las siguientes apreciaciones: puede ser considerado en un sentido amplio o en un sentido restringido. En sentido amplio asume, una significación semejante a teoría; se trataría de entender a toda teoría científica como modelo conceptual. En sentido restringido, el término modelo es una representación auxiliar que ilustra determinadas relaciones. En este caso, se establece entre teoría y modelo una diferenciación de nivel de abstracción ya que la primera supone un alto nivel de formalización mientras que el modelo se constituye en el instrumento básico para la construcción formal de aquella.

En este trabajo consideraremos el término modelo en sentido restringido, es decir como construcción que representa en forma simplificada la realidad o fenómenos de la misma, con el objetivo de delimitar las variables interactuantes más significativas y aportar posibles explicaciones e interpretaciones como constructos precursores de la teoría. Un modelo está caracterizado por su provisionalidad y por consiguiente, debe someterse a revisión continua. Los modelos no son más que mapas aproximativos de la realidad.

Son notas fundamentales de un modelo:

- Reproductividad: puesto que intenta ser la proyección de algo.

- Reducción: puesto que nunca pueden representarse todas las variables de la compleja realidad que se intenta proyectar.

- Subjetividad: puesto que implica optar, seleccionar dichas variables según la comprensión del hombre, de sí mismo y del mundo.

Resulta evidente recordar que tanto enseñantes como aprendices poseen historias de vida, experiencias, intereses y necesidades bien diferentes. Esto se refleja en las interacciones que se producen entre enseñanzas y aprendizajes. Estas apreciaciones nos obligan a realizar una serie de jerarquizaciones con referencia a la situación didáctica: 
- Es un fenómeno centrado en la persona.

- Se origina esencialmente en la interacción.

- Tiene intencionalidad.

- Exige climatización afectiva.

Nos gustaría detenernos en estos dos últimos puntos: intencionalidad y climatización afectiva. Con referencia a la primera, podemos decir que en la situación didáctica se da un proceso esencialmente cíclico: no existe unidireccionalidad estática; continuamente enseñante y aprendiz se enriquecen. Por ello el docente crece en su función de brindarse. En ese proceso siempre existe - implícita o explícitamente - un propósito o intención: la búsqueda del hombre hacia su autorrealización (Maslow, 1979).

La tendencia a la realización del sí mismo se alimentará y percibirá sólo en una atmósfera que no imponga, ordene o empuje autoritariamente al que aprende ni al que enseña, sino por el contrario, en la que aparezcan libres de presiones, en la que reine al máximo la espontaneidad personal, tanto de alumnos como de docentes. Desde esta perspectiva teórica, entonces, emprendimos el trabajo de investigación.

\section{Metodología}

Entendiendo por metodología la forma de encarar un problema, de buscar las respuestas y la manera de realizar la investigación, son los intereses y supuestos del investigador los que determinan la elección. Dentro de las perspectivas teóricas que han prevalecido en el marco de las ciencias sociales, se considera más ajustada a los propósitos de la investigación la perspectiva fenomenológica.

En un sentido amplio el término fenomenología designa una tradición de las ciencias sociales preocupada por la comprensión del marco de referencia del actor social. Se pretende entender los fenómenos sociales desde la propia perspectiva del actor. La realidad que importa es la que las personas perciben como importante. La conducta humana es producto del modo en que la gente define su mundo y el investigador busca aprehender este proceso de interpretación, para lo que recurre a métodos cualitativos.

Esta metodología, que produce datos descriptivos, se caracteriza por una serie de elementos:

* Es inductiva ya que desarrolla conceptos, comprensiones partiendo de pautas de los datos y no recogiendo datos para evaluar hipótesis o teorías preconcebidas.

* La perspectiva frente a los diferentes actores es holística, ya que se estudian en el contexto de la situación en que se hallan.

* Es esencial experimentar la realidad tal como otros la experimentan, para poder comprender

como ven las cosas dentro del marco de referencia de ellos mismos.

* Nada se da por sobreentendido, todo es tema de investigación.

* Para los investigadores cualitativos todas las perspectivas resultan valiosas, todos los escenarios y personas son dignos de estudio. Son a la vez similares y únicos (Taylor y Bogdan, 1987). 


\subsection{Universo y muestra}

Se entiende por universo a la totalidad de individuos o elementos en los cuales puede presentarse determinada característica susceptible de ser estudiada. No siempre es posible contemplar el universo en su totalidad, por esto es que, en el proceso de definición de la población y dependiendo de algunos criterios, es necesario seleccionar una parte de ese universo para llevar a cabo el estudio. Esa parte o subconjunto de la población se denomina muestra o población muestral.

En este trabajo de investigación la muestra fue no probabilística de tipo intencional. El muestreo no probabilístico no sigue el proceso aleatorio; se caracteriza porque el investigador selecciona su muestra siguiendo algunos criterios identificados para los fines del estudio que le interesa realizar. En el tipo intencional, el investigador, según sus objetivos, decide los elementos que integran la muestra, considerando aquellas unidades supuestamente "típicas" de la población que desea conocer. Cabe señalar que en este caso los investigadores ya han desarrollado trabajos en el área, y además por desempeñar tareas en el ámbito de la formación docente, pueden identificar "casos típicos" con referencia a las instituciones educativas y a los objetivos planteados. En el presente estudio la muestra estuvo integrada por docentes de cuatro instituciones de educación primaria de Montevideo. En cada una de estas instituciones educativas se convirtieron en informantes los maestros de primeros, terceros y sextos años. Esto permitió tener una visión de los diferentes momentos de la etapa escolar.

\subsection{Preguntas iniciales}

¿Cuáles son las maneras o formas (configuraciones didácticas) que los docentes tienen de enseñar la lectura y la escritura en el nivel primario?

¿Cuáles son los fundamentos teóricos de esas maneras o formas de enseñar?

Las posturas teóricas dominantes en las escuelas primarias con referencia a la enseñanza de la lectura y la escritura ¿corresponden con las concepciones más aceptadas hoy día en ese campo del saber?

¿Los docentes utilizan variados textos para acercar al niño al contexto de la lectura y la escritura?

\subsection{Instrumentos para la colecta de la información}

La observación simple y la entrevista no estructurada han sido los instrumentos definidos para la colecta de información. El equipo de investigadores discutió sobre los criterios para su elaboración. Luego de varias reuniones de trabajo se definieron parámetros y distinciones para las observaciones simples y se elaboraron algunas pautas para las entrevistas. Para validar este diseño se realizaron estudios pilotos con sujetos que presentaban similares características a los que integran la muestra. La finalidad de estos estudios fue comprobar la eficacia y pertinencia del diseño del instrumento. Sirvió, además, para realizar algunas reformulaciones a la técnica originalmente creada. Entre los meses de setiembre y noviembre se efectuó la colecta de información en las instituciones educativas seleccionadas.

Para poder abarcar los tres grados escolares seleccionados fue necesario realizar varias observaciones. En todos los casos los grupos fueron visitados cuatro veces. Una vez concluida la clase se realizaban reuniones con los maestros para hacer una devolución de lo observado, de esta manera se trabajaba sobre un aspecto polémico de la investigación cualitativa: la validación del instrumento; estos encuentros con los docentes oficiaron como "triangulación metodológica" (Taylor y Bogdan, 1987). Estas reuniones fueron aprovechadas para compartir los registros y para controlar la subjetividad del observador. Siempre que fue posible, además de la observación y la entrevista, se recolectó información a través de las producciones de los nilios y la planificación del docente. 
El procedimiento de observación contempló tres fases o momentos:

a- Operación de identificación de los hechos, lo cual supone una selección de los hechos para determinados objetivos y una codificación, operación lingüística de atribución de una palabra o frase que califica al objeto.

b- Construcción de una red de relaciones entre los hechos. Por ejemplo: vínculos de identidad, vínculos causales, entre otros.

c- Interpretación: modelo de proceso, estructuras internas, noción de repetibilidad en función del paradigma seleccionado.

Las entrevistas se realizaron simultáneamente con las observaciones. El efecto "bola de nieve" (Taylor y Bogdan, 1987) se hizo presente: un informante llevaba a otro y así sucesivamente. Maestros, y también alumnos, aportaron información sobre: qué era para ellos escribir y leer; por qué lo hacían; qué tipos de textos leían; cómo leían; qué tipos de textos escribían; qué procesos de enseñanza validaban los maestros en el momento de desarrollar las competencias comunicativas de sus alumnos, etc. En algunos casos estas entrevistas sirvieron para confirmar hechos y actitudes registradas en las observaciones; en otros casos, estas entrevistas se utilizaron para profundizar sobre discrepancias entre lo observado y lo manifestado en la propia entrevista. La duración de las mismas dependió del informante; en algunos casos fue necesario reiteradas interacciones cara a cara para poder abarcar todos los temas propuestos.

\section{El análisis de la información}

Es difícil expresar las influencias que surgen al hacer el análisis. En el proceso de investigación hemos leído y releído los registros, así como el marco teórico; se construyeron categorías; se confrontaron con más lectura de teoría y con más trabajo de campo. Sistematizamos la información en diversos momentos y lugares (con miembros del colectivo docente, con asesorías específicas de otros investigadores en el área); esta sistematización se da en un ir y venir entre la información obtenida en el trabajo de campo que en su mayoría son registros etnográficos y entrevistas - con la articulación de categorías analíticas que en ocasiones son también categorías sociales - y con la reflexión colectiva. La construcción toma varios momentos:

- el primer contacto que se hace con la realidad

- la construcción colectiva - en donde se recogen elementos teórico-prácticos

- la construcción final.

Siempre fue necesario volver a los registros de campo, reflexionar en conjunto para finalmente obtener una descripción analítica. 


\subsection{Categorías de análisis}

En función de las dimensiones de análisis definidas en el proyecto inicial, se elaboraron las siguientes categorías, respaldadas en el marco teórico oportunamente desarrollado, que procuran mostrar las formas o maneras que los docentes ponen de manifiesto en el momento de enseñar lengua escrita. Algunas de ellas se vinculan de manera más directa con las propuestas de enseñanza en las situaciones didácticas, otras informan sobre los materiales utilizados para enseñar a leer y escribir y finalmente otras refieren a las concepciones de lectura y escritura.

\subsubsection{Con referencia a las propuestas de enseñanza}

En esta categoría de análisis, que refiere específicamente a las formas de intervención del docente en el proceso de enseñanza, fue posible encontrar subcategorías vinculadas con:

\subsubsection{Explicitación en las propuestas de enseñanza, por parte de los docentes, de saberes que están implícitos en las prácticas de lectura y escritura}

En la investigación se ha encontrado que con frecuencia el maestro manifiesta una postura predominantemente declarativa sobre aspectos de la lengua. Esta función declarativa del discurso se refleja cuando el docente, en el momento de enseñar, trata de explicar la práctica de la lengua escrita en forma a priori. Por ejemplo:

(Contextualización: la cita está tomada de un registro de clase de 1er. Año. Se trata de un grupo de 30 niños. En el salón hay varias mesas, los niños se sientan en grupos de cuatro o cinco por mesa. Los pequeños grupos generalmente son mixtos. Uno sólo de ellos es exclusivo de niñas. En el aula hay varias carteleras. Una de ellas posee material sobre la declaratoria de la independencia. Otra cartelera informa sobre la llegada de la primavera. Hay dos bibliotecas en el salón; poseen libros de cuentos y poemas, revistas, diccionarios y enciclopedias. Sobre el pizarrón se encuentra el abecedario. En un costado hay un almanaque y en el otro costado la lista de nombres de alumnos de la clase. Los niños tuvieron unos días de asueto por primavera. Si bien hace unos días de ello, aún le cuesta un poco a la maestra orientar las tareas. En la clase pasada estuvieron hablando sobre lo que habían hecho en esos días. En la clase de hoy se desarrollaría una actividad de escritura sobre ese mismo tópico. La maestra consulta a los alumnos sobre lo que habían comenzado a hacer en la clase pasada. Problematiza la situación señalando que como no recuerda lo que le habían contado y como son muchos para poder hablar, es necesario desarrollar ese evento comunicativo a través de otro canal. Una niña dice : Te podemos escribir. Ante esta respuesta la maestra interviene)

"Mtra- Bien Florencia, escribir. Esa es una de las funciones de la escritura: no lo podemos decir oralmente porque somos muchos y como todos queremos hablar y no tenemos mucho tiempo, entonces lo escribimos. Y eso es lo que vamos a hacer ahora. Vamos a tomar una hoja, yo les voy a entregar una hoja y cada uno de ustedes me van a contar lo que estuvo haciendo en esos días hermosos de vacaciones que tuvimos. ¿Quieren?"

(Cita tomada de registro de clase - observación- maestro de 1A)

"Edor.- Es frecuente en tu práctica de enseñanza explicar previamente sobre cómo se desarrollaría tanto el proceso de lectura como el de escritura. Es decir contás sobre cómo se lee y sobre cómo se escribe ¿Es muy frecuente esa propuesta de enseñanza? ¿Por qué la hacés?

Eda.- Sí, es muy frecuente. A mí me parece que es una buena manera de enseñar. Creo que primero le tenés que explicar cómo se lee y se escribe. Es una manera, creo yo, de reflexionar sobre el proceso".

(Cita tomada de una entrevista- maestro de 3A) 


\subsubsection{Selección, por parte del docente, de algunas intervenciones de los alumnos que le sirven para continuar con su propuesta de enseñanza}

Las intervenciones de los docentes se orientan a buscar información en los alumnos sobre las prácticas de lectura y escritura, pero sólo seleccionan las que le sirven para su enseñanza, dejando de lado toda aquella otra intervención que no se ajuste a su propuesta didáctica. Por ejemplo:

(Contextualización: la cita está tomada de un registro de clase. Se trata de un primer año, grupo de 32 niños. Están sentados en fila. En el salón hay biblioteca. Las dos carteleras tienen información sobre: el abecedario, el invierno y la declaratoria de la independencia. En una de las paredes hay un afiche sobre el niño lector. Están trabajando con el libro de segundo año - Leer es un derecho - . En la página 90 de ese texto hay un juego. La presencia de éste genera la inquietud en los niños de construir otros juegos)

"N (Niño)1 - Entonces no podemos hacer otro juego.

Mtra.- Claro que sí, pero tenemos que definir primero para qué y por qué lo queremos hacer.

N2- ¿Y si hacemos un juego sobre la salud pero con monstruos como los de las maquinitas?

N3 (Martín)- Primero tenemos que ver cómo se hacen los juegos.

Mtra.- Martín ¿Por qué te parece que tenemos que saber primero cómo se hacen los juegos?

N3 (Martín) - Porque si no podemos explicar cómo se juega nadie lo va a entender.

Mtra.- Bien. Entonces vamos a ver cómo se escriben las instrucciones que acompañan un juego".

(Cita tomada de registro de clase - Observación - maestro de 1C)

"Eda.- Los chiquilines intervienen mucho... eso es muy bueno...porque te muestran que están interesados en el trabajo.

Edor.- ¿Y tenés en cuenta todas las intervenciones de los chiquilines?

Eda.- Sí, por supuesto.

Edor.- ¿Aunque no aporten al tema que estás enseñando?

Eda.- Bueno ....en realidad creo que todo docente, no sé, por lo menos yo... selecciono aquellas intervenciones que me ayudan a plantear el tema.

Edor.- ¿Cómo es eso? ¿Me lo podrías explicar?

Eda.- Claro...tomo lo que me va permitiendo ir avanzando. No sólo tomo lo que está bien, también lo que está mal...pero claro que lo que está bien te ayuda mucho más. Como que te facilita la tarea.

(Cita tomada de una entrevista - maestro de 3B). 


\subsubsection{Situaciones donde los maestros muestran prácticas de lectura y escritura en toda su complejidad}

En el análisis preliminar de la información hemos encontrado algunas situaciones didácticas que muestran a los enseñantes como verdaderos usuarios de la lengua escrita; los maestros toman esas instancias como ámbitos de privilegio para desarrollar procesos de enseñanza. Las siguientes citas ilustran esta categoría de análisis:

"(La Maestra está leyendo una revista; no oraliza el texto; en algunos momentos se detiene y retoma párrafos anteriores. Algunos niños ven cómo lee su maestra y le dicen)

N- ¿Vos te olvidás de lo que dice por eso tenés que volver atrás?

Mtra.- Sí, algunas veces no logro comprender una idea y tengo que leer una y otra vez para poder comprender.

N- $\quad$ Y si es un libro muy largo ¿Te lo leés todo de nuevo?

Mtra.- Algunas veces sí. Eso depende de lo que no haya entendido o de lo que no me acuerde".

(Cita tomada de registro de clase - Observación - maestro de 3D)

"Mtra. Y sí, yo creo que para poder enseñar bien a leer y escribir uno tiene que ser lector y escritor. Creo que eso sucede con cualquier cosa que se quier enseñar. Si no sabés y si no lo hacés resulta difícil enseñarlo.

Edor.- ¿Qué implica ese ser lector y escritor?

Mtra.- Significa que tenés que leer y escribir si querés entender realmente lo que implica hacer eso. Por ejemplo, si vos decís que al escribir es importante el borrador porque te permite planificar la escritura, creo, a mí me parece, que es buena idea hacer eso frente a los alumnos. En otras palabras, escribir con los niños, que te vean cómo lo hacés".

(Cita tomada de una entrevista - maestro de 1E)

\subsubsection{Intervenciones del docente para controlar la situación didáctica}

Las intervenciones del docente buscan información para controlar la situación didáctica. Esos controles sirven al maestro para continuar/replantear su propuesta de enseñanza. Por ejemplo:

(Contextualización: el registro pertenece a una clase de 3er. Año. Una de las niñas falta desde hace unos días porque está enferma; la maestra toma esta situación e invita a los niños a que le escriban a efectos de contarle lo que han estado realizando tanto en la escuela como en sus casas. Al comenzar la tarea da algunas pautas sobre cómo escribir; enfatiza la importancia de los borradores y la consulta a otros cuando hay dudas sobre el proceso de escritura. La docente recorre el salón y observa lo que cada niño está escribiendo) 
"Mtra.- Joaquina ¿puedo leer lo que estás escribiendo? ( La niña le ofrece el texto; la maestra lo lee, hay apenas dos renglones. Uno de ellos es la fecha que ha copiado del pizarrón)

Mtra.- ¿ ¿Y qué más vas a poner?

Joaquina - Que fui a jugar a lo de Julieta y que fuimos a comer pizza y que jugamos en el pelotero.

Mtra.- ¡Qué lindo! ¿Te divertiste mucho?

(La niña contesta con la cabeza; ha recuperado su hoja y sigue escribiendo. No consulta a sus compañeros ni vuelve, durante la clase, a su maestra para evacuar dudas. Borra con frecuencia y oraliza lo que va escribiendo).

(Cita tomada de registro de clase - Observación - maestro de 3D)

"Mtra.- Como que tenés que ir viendo qué es lo que van escribiendo para poder ayudarlos... me parece, porque si los dejás y no intervenís como que se pueden ir por cualquier lado.

Edor.- ¿Me podrías relatar alguna experiencia en ese sentido para poder comprender mejor ese acompañamiento?

Mtra.- Y sí, te cuento por ejemplo... yo que trabajo con tercer año a veces se les da por escribir y escribir y pierden el hilo... terminás por no entender nada porque aquello que inicialmente iba a ser un texto, es algo incoherente y con poca organización. Entonces para que no pase eso yo voy controlando lo que van poniendo, así cuando aparecen esos desvíos se los hacés ver y los corregís".

(Cita tomada de una entrevista - maestro de 3D)

\subsubsection{Con referencia a los materiales utilizados para enseñar a leer y escribir:}

\subsubsection{Textos de uso social}

Variedad y diversidad de textos son manejados generalmente por los maestros en el momento de enseñar lengua escrita. Es así que aparecen afiches, cartas, libros de cuento, enciclopedias, recetas, entre otros materiales, en el momento de "mostrar" la funcionalidad de la lengua escrita. Si bien existe diversidad y variedad, es posible observar un ligero predominio de textos literarios. A modo de ejemplo de la variedad textual se presentan las siguientes situaciones:

"Mtra.- Vean que en este texto también aparece el concepto de promedio ¿Es el mismo concepto de promedio que trabajamos en la clase pasada, con el recibo de UTE?

N - $\quad$ No, porque aquel era con números y te decía lo que gastaste de luz en el mes y este dice de los promedios de los olores pero no hay números".

(Cita tomada de registro de clase - Observación maestro de 6A). 
"Mtra.- Bueno, luego de cantarle a Martín por su cumpleaños, vamos a comenzar a trabajar. Uds. se acuerdan que habíamos quedado que hoy íbamos a continuar con el afiche sobre el tránsito. Habíamos estado hablando de lo importante de prestar atención a las señales de tránsito para evitar accidentes".

(Cita tomada de registro de clase - Observación maestro de 3B)

"Mtra.- Me gusta trabajar mucho en forma colectiva, si bien el proceso de escritura es particular, uno escribiendo con otro se enriquece. Además trato siempre que sea posible de trabajar con diversos textos, por ejemplo recetas, reglas de juegos, afiches, cartas, cuentos, enciclopedias".

(Cita tomada de una entrevista - maestro de 1D)

"Mtra.- ¿Quién me puede contar lo que hicimos la clase pasada?

N.- Trabajamos haciendo cuentas.

Mtra.- ¿YY qué más hicimos?

N.- Escribimos

Mtra.- ¿Algo más?

N.- Leímos.

Mtra.- ¿Qué leímos?

N.- Revistas"

(Cita tomada de registro de clase - Observación de maestro de 1B)

\subsubsection{Textos de uso escolar}

El libro de texto también se ha hecho presente como un recurso para enseñar lengua escrita. Definimos libro de texto como aquellos materiales elaborados intencionalmente con el propósito de convertirse en recursos para la enseñanza y en este caso en particular, para la enseñanza de la lengua escrita. Desde el propio sistema educativo se incentiva el uso de este tipo de material. Veamos los siguientes ejemplos detectados en la colecta de datos.

"Edor.- ¿Y con los libros de lenguaje? ¿También los usás?

Mtra.- Sí, claro... no los impongo. Creo que hay que saber usarlos. Es decir... tenés que seleccionar aquellos textos que te sirvan para lo que estás dando

Edor.- Es decir...vos en función del tema que estás dando ves qué texto te sirve.

Mtra.- Más o menos. 
Edor.- ¿Por qué más o menos?

Mtra.- Bueno... sí, en realidad sí".

(Cita tomada de una entrevista - maestro de 3D)

\subsubsection{Escolarización de textos de uso social}

Esta categoría se define en función de que al realizar el análisis de los datos pudimos comprobar que en algunos casos los maestros transforman los textos sociales en textos escolares. Los ejemplos que acompañan esta categoría pueden ilustrar mejor el fenómeno.

[Clase de $3^{\circ}$. Año. Grupo de 34 niños. Los bancos están distribuidos en fila. Hay poco espacio; el número de alumnos es mayor que el que puede tener el aula. Hace una semana que están en este nuevo salón. No hay carteleras ni biblioteca de aula. Este traslado ha generado tanto en alumnos como en la maestra un gran malestar que se pone de manifiesto en las diferentes conversaciones. Ese día ha llegado a saludar al grupo la practicante Marian. Ha estado enferma y desde hace una semana no venía a la escuela; ese mismo día se enteró del cambio de salón. Marian está ahora con otro grupo. Los niños le hicieron saber lo molestos que estaban por ese cambio. Le piden que intervenga y que haga algo para poder volver al otro salón. Uno de los niños sugiere hacer huelga; otros proponen hacer una pancarta para poner frente a la dirección. Este tema es tomado por la maestra y los invita a escribir una nota donde reflejen su malestar y donde además se proponga algún tipo de solución para el problema].

(La mayoría de los niños gritan, algunos golpean las mesas en señal, aparentemente, de protesta porque no quieren escribir la carta; prefieren ir hablar con la directora. La maestra trata de hablar pero no la dejan. Hace gestos para que se callen).

Mtra.- Bueno, calma, calma, a todos nos preocupa este tema pero eso no implica que no podamos trabajar de manera ordenada. Entonces quedamos en que vamos a escribir una carta donde argumentemos por qué necesitamos ir a un salón más grande. ¿Qué les parece si escribimos una carta juntos? Uno de Uds. pasa al pizarrón y todos cooperamos en la elaboración de la nota. ¿Sí?”

(Cita tomada de registro de clase - Observación- maestro de 3 E)

\subsubsection{Con referencia a las concepciones de lectura y escritura en el discurso y en las prácticas de enseñanza}

Los procesos de enseñanza evidencian las concepciones que los docentes tienen sobre los saberes. En este caso las propuestas didácticas manifiestan las ideas que los maestros poseen sobre la lectura y la escritura. Del análisis de los datos se desprenden algunas discrepancias sobre las concepciones que ponen de manifiesto en las prácticas áulicas y las que formulan en el discurso sobre esas mismas prácticas áulicas. Los siguientes ejemplos muestran la situación: 


\subsubsection{La lectura como conjunto de habilidades}

Esta categoría de análisis pone en evidencia una concepción de lectura como proceso divisible, segmentado tanto en la enseñanza como en el aprendizaje. Esta concepción, en auge hace unas cuantas décadas, aflora en las prácticas y discursos de algunos docentes.

"Mtra.- Yo creo que la lectura y la escritura, bueno ... los conceptos han ido cambiando a lo largo de estos años. Ya hemos aprendido que leer no es oralizar, pero como que es difícil en el momento de enseñar, de estar con el niño. En la teoría una lo comparte pero en la práctica...como que faltan orientaciones didácticas, que te ayuden a enseñar de otra manera,... no sé, tal vez haya pero yo no las conozco o no me las han dado a conocer.

Edor.- $\quad$ Así que se comparten estas nuevas concepciones en el plano teórico pero llegado el momento de enseñar como que resulta difícil su implementación ¿Y será que realmente se comparten? ¿No surgirán esas dudas en la práctica por no tenerlas incorporadas realmente?

Mtra.- $\quad$ Y tal vez sí, no sé...no lo tengo muy pensado y analizado. Lo que sí tengo claro es que en el discurso la mayoría decimos que hacemos y enseñamos en el marco de ciertas concepciones... de las concepciones más aceptadas hoy día. La mayoría de las maestras han leído a Dubois, a Jolibertt, a Lerner...pero qué querés que te diga. En el momento de enseñar como que volvemos a como aprendimos nosotros... de la letra a la palabra. De eso estamos seguros.

Edor.- ¿Y esas maneras de enseñar son contradictorias con las concepciones de lectura y escritura que, por ejemplo, postulan esas autoras que nombraste?

Mtra.- Claro que sí.

Edor.- $\quad$ Y si estás tan segura ¿por qué no cambiás? Es decir, ¿por qué no buscás una coherencia entre lo que se dice y lo que se hace?

Mtra.- Si fuera tan fácil... creo que lo he buscado, que lo busco...pero necesito que me orienten en esa nueva manera de enseñar a leer y escribir".

(Cita tomada de una entrevista- maestro de 1E)

\subsubsection{La lectura como proceso transaccional}

Esta categoría de análisis pone en evidencia una concepción de lectura donde el lector es un sujeto activo en el proceso: transforma al texto pero él también es transformado por el texto. No se presenta el acto de lectura como un proceso divisible sino como un encuentro único, irrepetible y infragmentable.

"(La Maestra está leyendo una revista; no oraliza el texto; en algunos momentos se detiene y retoma párrafos anteriores. Algunos niños ven cómo lee su maestra y le dicen) 
$\mathrm{N}$ - ¿ ¿Vos te olvidás de lo que dice por eso tenés que volver atrás?

Mtra.- Sí, algunas veces no logro comprender una idea y tengo que leer una y otra vez para poder comprender.

$\mathrm{N}$ - $\quad$ Y si es un libro muy largo ¿ ¿Te lo leés todo de nuevo?

Mtra.- Algunas veces sí. Eso depende de lo que no haya entendido o de lo que no me acuerde".

(Cita tomada de registro de clase - Observación - maestro de 3D)

\subsection{Discusión y conclusiones}

A partir de este análisis de datos, y recordando el carácter exploratorio y descriptivo de la investigación así como su diseño metodológico fuertemente cualitativo, podemos contestar a nuestras preguntas iniciales de la siguiente manera:

Coexisten diferentes y contradictorias propuestas de enseñanza de la lectura y la escritura en las prácticas y en los discursos de los maestros que constituyeron la muestra de este trabajo de investigación. La biografía escolar (su historia como alumno), la socialización profesional (su experiencia laboral) adquieren una relevancia en el momento de pensar prácticas de enseñanza. Esa relevancia es tal que muchas veces termina por neutralizar la biografía profesional (es decir, su historia en el Instituto de Formación Docente) que le podría haber presentado nuevas concepciones sobre estos saberes y sobre las formas de enseñar y aprender. Concepciones mecanicistas de la lectura y la escritura se entrecruzan con posturas paradigmáticas de corte transaccional; la duda y la incertidumbre impiden muchas veces transitar por nuevas propuestas didácticas. Enseñar como me enseñaron en la escuela, parece ser un rasgo muy marcado en la matriz conceptual de algunos docentes.

Del análisis de los datos también se desprende que las nuevas concepciones de lectura y escritura aún no han ingresado con fuerza en el aula primaria. La lectura como conjunto de habilidades y la dimensión psicomotriz en la escritura ocupan un lugar de privilegio en las propuestas de enseñanza. Estas concepciones unidas a variadas y algunas veces contradictorias maneras de entender los procesos de aprendizaje, conllevan a generar algunas dificultades en el momento de conectar los procesos de enseñanza con los de aprendizaje. Para poder establecer un contrato didáctico entre aprendices y enseñantes es requisito que se tiendan puentes de ambos lados; es necesario que las concepciones de enseñanza estén en armonía y sintonía con las concepciones de aprendizaje. Si esto no se logra, no habrá contrato didáctico y sí se manifestarán ejemplos de discontinuidad pedagógica.

Con referencia a la utilización de textos para la enseñanza de la lectura y la escritura, y en función de los datos recolectados, podemos señalar que hay intentos de proporcionar al niño variedad y diversidad de textos. En esa diversidad y variedad están tanto los textos sociales como los escolares. Las prácticas analizadas informan de una etapa de transición denunciada a través de la escolarización de textos sociales. Fundamentamos esta aseveración al observar una preocupación por parte de los maestros de mostrar en el aula textos que circulan en la comunidad, pero el contexto de presentación o la manera de utilizarlos determina muchas veces una banalización de los mismos.

La intención de esta pesquisa fue describir prácticas de enseñanza de la lengua escrita en doce maestros de escuelas primarias; estas reflexiones no deben, teniendo en cuenta el modelo de investigación seleccionado, ser generalizadas. No obstante muestran el estado de situación en determinados centros 
educativos que son claves en el momento de pensar la formación de los docentes. No obstante estas reflexiones, lo que también se advierte en las prácticas de enseñanza de la lectura y la escritura en el nivel primario, es un gran deseo de los maestros por actualizarse y por incorporar fundamentadas innovaciones didácticas. Tal vez el lento proceso de modificación de sus propuestas de enseñanza pueda explicarse por esa necesidad de tener un buen respaldo y argumento para cambiar sus maneras de enseñar.

\section{Algunas sugerencias}

No es ánimo de este trabajo presentar una lista de recomendaciones sobre la buena enseñanza de la lectura y la escritura. Pero la información obtenida, nos habilita a pensar juntos. En este sentido es que planteamos lo siguiente:

- Para favorecer el desarrollo de la competencia comunicativa de los niños es necesario organizar las prácticas de enseñanza de la lectura y la escritura desde una perspectiva de continuidad; esto significa que es necesario acuerdos teóricos y de intervención didáctica, entre maestros de un mismo grado y entre maestros de los diferentes grados.

- Para poder cumplir con lo anterior es necesario que el gestor del centro educativo asuma un liderazgo pedagógico y convoque a encuentros teóricos, a efectos de que se pueda insertar en el proyecto de centro un proyecto de enseñanza de las prácticas lingüísticas.

- El desarrollo de las competencias comunicativas también se verá favorecido por la existencia en cada institución de espacios alfabetizadores: bibliotecas escolares, bibliotecas áulicas, bibliotecas viajeras (de la escuela a la casa de los niños), abundantes carteleras, muestras de libros, exposiciones de material impreso, ferias de libros, visitas de escritores (que serán utilizadas no sólo en su dimensión social, sino fundamentalmente como una instancia de enseñanza y aprendizaje), etc.

- Para poder impulsar las propuestas anteriores es necesario pensar en estrategias de actualización y perfeccionamiento docente.

- Resulta imposible pensar en impulsar cambios e innovaciones didácticas con un colectivo docente que no los sienta como una necesidad o no posea un domino en esa área de conocimiento.

-Un buen docente se caracteriza, además de por su comunicabilidad didáctica, por ser un informante competente sobre el objeto de conocimiento que enseña, por favorecer ambientes de aprendizaje y por indagar/investigar sobre sus prácticas áulicas.

- Poner la atención en este último aspecto, investigar sobre sus intervenciones didácticas, puede ser un buen camino para revisar las formas y maneras de enseñar. Un insumo básico para pensar propuestas de enseñanza es indagar, entre otros aspectos, sobre cuándo, por qué, para qué lee/escribe el docente. Nadie puede enseñar lo que no sabe o no siente.

- Los programas de actualización y perfeccionamiento docente deberían ser impulsados desde los propios organismos educativos nacionales, insertando las diferentes modalidades en un eje teórico práctico estructurante: el maestro lector y escritor.

- Diferentes investigaciones sobre los aprendizajes de los niños en edad escolar informan que aún no han logrado un nivel de aceptabilidad en las prácticas de lectura y escritura, por tanto estos programas de actualización y perfeccionamiento docente podrían revertir, al menos parcialmente, la situación. 


\section{Bibliografía}

Blanchet, A.; y otros 1989 Técnicas de investigación en ciencias sociales. Madrid, Narcea.

Camilloni, A.; y otros 1995 Corrientes didácticas contemporáneas. Buenos Aires, Paidós.

Chevallard,Y. 1997 La transposición didáctica. Buenos Aires, Aique.

Davini, M. C. 1996 La formación docente en cuestión: política y pedagogía. Buenos Aires, Paidós.

Ketele, J. M.; Roegiers, X. 1995 Metodología para la recogida de información. Madrid, La Muralla.

Dubois, M. E.1990 El proceso de lectura. Buenos Aires, Aique.

Litwin, E. 1997 Las configuraciones didácticas. Buenos Aires, Paidós.

Martínez, M. 1991 La investigación cualitativa etnográfica en educación. Caracas, Texto.

Maslow, A. 1979 El hombre auto-realizado. Barcelona, Kairós.

Pardinas, F. 1996 Metodología y técnicas de investigación en ciencias sociales. Madrid, Siglo XXI.

Porland, R.; Martín, J 1993 El diario del profesor. Un recurso para la investigación en el aula. Sevilla, Díada.

Postic, M.; Ketele, J. M. 1988 Observar las situaciones educativas. Madrid, Narcea.

Rosenblatt, L. 1996 El modelo transaccional de la lectura y la escritura. Buenos Aires, Lectura y Vida.

Smith, F. 1994 Writing and the writer. Nueva York, Holt.

Taylor, S.; Bodgan, R. 1987 Introducción a los métodos cualitativos de Investigación. Buenos Aires, Paidós.

UNESCO/OREALC 1993 Proyecto Principal de Educación en América latina y el Caribe. Boletín No.30, Santiago de Chile, UNESCO/OREALC.

Vázquez, A. 1999 En busca de la enseñanza perdida. México, Paidós.

Wolff, L.; Schiefelbein, E.; Valenzuela, J. 1993 Mejoramiento de la calidad de la educación primaria en América Latina y el Caribe; hacia el siglo XX. Informe No. 28, BID.

Woods, C. "La lecto-escritura en las interacciones: una búsqueda de las dimensiones y significados en el contexto social". En: Ferreiro, E. y Gómez Palacio; M.1986 Nuevas perspectivas sobre los procesos de lectura y escritura. México, Siglo XXI, pp. 321-345.

Woods, P. 1989 La escuela por dentro. La etnografía en la investigación. Madrid, Paidós 
* Magister en Educación. Profesora y tutora en el Instituto de Educación, Universidad ORT.

** Maestra directora. Profesora de Lectura y Escritura en Formación Docente.

*** Maestra. Profesora de Lectura y Escritura en Formación Docente.

**** Lingüista y didacta. Secretario Docente del Instituto de Educación, Universidad ORT 